\title{
Natural Habitat of Aureobasidium pullulans in Sari, Iran
}

\author{
Mehdi Taheri Sarvtin $^{1, *}$; Ali Asghar Alamian ${ }^{2}$ \\ ${ }^{1}$ Department of Medical Mycology and Parasitology, School of Medicine, Jiroft University of Medical Sciences, Jiroft, IR Iran \\ ${ }^{2}$ Department of Medical Mycology and Parasitology, School of Medicine, Mazandaran University of Medical Sciences, Sari, IR Iran \\ *Corresponding author: Mehdi Taheri Sarvtin, Department of Medical Mycology and Parasitology, School of Medicine, Jiroft University of Medical Sciences, Jiroft, IR Iran. Tel: \\ +98-9132489448, Fax:+98-3482318084, E-mail: mehditaheri.mt@gmail.com
}

Received: July 13, 2014; Revised: October 20, 2014; Accepted: December 30, 2014

Keywords: Fungi; Spore; Wood

Aureobasidium pullulans is a potentially pathogenic black yeast-like and halotolerant fungus causing everincreasing diseases (1), such as infections, pulmonary problems, especially allergy due to respiratory irritation mediated by cell-wall components (e.g. glycoproteins, beta-glucans) in patients with respiratory diseases, children, old people, and immune-compromised patients $(2,3)$. The occurrence of A. pullulans has been mostly reported in temperate climates (4). However, it has been also found in Denmark, Canada, Germany, Alaska, Antarctica, the Netherlands, Austria, Poland, Czechoslovakia, and Russia (4). In various studies, soil, air, woods and wood products have been reported as habitats of A. pullulans (5-7).

Sari is a major city in north of Iran with humid and temperate climate. So, in this study, the presence of A. pullulans was examined in soil, air, wood, and wood products used inside of the buildings in Sari City. This investigation was carried out from September 2013 to March 2014 in the department of medical mycology, school of medicine, Mazandaran University of Medical Sciences, Sari, Iran. The airborne fungal spores in indoor and outdoor of 17 houses were collected by sedimentation method. At the same time, 34 Petri dishes, $90 \mathrm{~mm}$ in diameter, containing Malt Extract Agar (MEA) (Merck, Germany) were opened and exposed to air about $1 \mathrm{~m}$ above the ground in different parts of the houses (Kitchen, living room, bedroom). Seventeen petri dishes were opened and exposed to air of outdoor around the houses. The fungal spores from wood and wood products were collected by scalpel and cultured on MEA medium. The soil fungal spores were isolated according to the procedure of Chowdhary et al. (8). All petri dishes were transferred to the laboratory and incubated at $25^{\circ} \mathrm{C}$ for 6 days. Fungal isolates were identified by conventional methods, including the gross morphology of the fungal colony and slide culture for microscopic characterization. Aureobasidium pullulans has smooth, blackish-brown thallus, covered with a slimy mass of pale brown spores becoming darker with the apparition of black filament. This fungus has undifferentiated conidiophores (or with short lateral branches) (4). Identification of all A. pullulans isolates were confirmed based on sequencing the D1/D2 domain of the 26S ribosomal RNA gene (9).

In Pitkaranta et al. (5), Cooke (6), and Horvath et al. (7) studies, A. pullulans was isolated from indoor air, soil, and wood products, respectively. In the present study, A. pullulans was only isolated from the wood and wood products. This difference may be due to variations in geographical region and diagnostic techniques. Wood is a biological material consisting of cellulose, lignin, and hemicellulose that in adequate moisture, A. pullulans can easily grow on and degrade the wood via its enzymes including: cellulose, pectinesterase, pectin transeliminase, pectinase, polygalacturonase, polymethylgalacturonase, xylanase and L-rhamnose dehydrogenase $(4,7,10)$. Penetration of this fungus can be rapid and growth over a 24 hour period has been measured as $1 \mathrm{~mm}$ radially, $0.5 \mathrm{~mm}$ tangentially, and $5.0 \mathrm{~mm}$ longitudinally (4).

In conclusion, wood and wood products are the only found natural habitat for A. pullulans in Sari, north Iran. Therefore, less use of wood and wood products in houses of sensitive individuals is recommended. Staining of the wood and moisture control methods used to inhibit wood decay fungi will also eliminate conditions favorable for the growth of A. pullulans.

\section{Acknowledgements}

The authors would like to acknowledge members of department of mycology, school of medicine, Jiroft University of Medical Sciences, Jiroft, IR Iran.

\section{References}

1. Tanioka A, Tanabe K, Hosono A, Kawakami H, Kaminogawa S, Tsubaki K, et al. Enhancement of intestinal immune function in mice by beta-D-glucan from aureobasidium pullulans ADK-34. Scand J Immunol. 2013;78(1):61-8. 


\section{Taheri Sarvtin M et al.}

2. Arzanlou M. Molecular Characterization of Aureobasidium Species in Iran. Res Mol Med. 2014;2(2):28-33.

3. Asano T, Tanaka K, Suemasu S, Ishihara T, Tahara K, Suzuki T, et al. Effects of beta-(1,3-1,6)-D-glucan on irritable bowel syndromerelated colonic hypersensitivity. Biochem Biophys Res Commun. 2012;420(2):444-9.

4. Gunde-Cimerman N, Ramos J, Plemenitas A. Halotolerant and halophilic fungi. Mycol Res. 2009;113(Pt 11):1231-41.

5. Pitkaranta M, Meklin T, Hyvarinen A, Paulin L, Auvinen P, Nevalainen A, et al. Analysis of fungal flora in indoor dust by ribosomal DNA sequence analysis, quantitative PCR, and culture. App Environ Microbiol. 2008;74(1):233-44.

6. Cooke WB. An ecological life history of Aureobasidium pullulans (de Bary) Arnaud. Mycopathol Mycol Appl.1959;12(1):1-45.

7. Horvath RS, Brent MM, Cropper DG. Paint Deterioration as a Re- sult of the Growth of Aureobasidium pullulans on Wood. Appl Environ Microbiol. 1976;32(4):505-7.

8. Chowdhary A, Kathuria S, Xu J, Sharma C, Sundar G, Singh PK, et al. Clonal expansion and emergence of environmental multipletriazole-resistant Aspergillus fumigatus strains carrying the $\mathrm{TR}(3)(4) / \mathrm{L} 98 \mathrm{H}$ mutations in the cyp51A gene in India. PLoS One 2012;7(12):e52871

9. Kurtzman CP, Robnett CJ. Identification and phylogeny of ascomycetous yeasts from analysis of nuclear large subunit (26S) ribosomal DNA partial sequences. Antonie van Leeuwenhoek. 1998;73(4):331-71.

10. Nasr S, Soudi MR, Hatef Salmanian A, Ghadam P. Partial Optimization of Endo-1, 4-Beta-Xylanase Production by Aureobasidium pullulans Using Agro-Industrial Residues. Iran J Basic Med Sci. 2013;16(12):1245-53. 